Research Article

\title{
Socio-demographic, Environmental and Life Style Factors on the Dengue Epidemic in Noakhali District, Bangladesh: Evidence from Recent Outbreak
}

\author{
Md. Ruhul Kabir', ${ }^{1,2}$ Nahian Rahman', Allama lqbal', Fahmida Azad', Shawon Hasan Tithi', \\ Muhammad Helal Uddin', Urme Mostary', Meraz Tanvir', Md. Zakaria Tanzim', \\ Md. Abdur Rob Mahim \\ ${ }^{1}$ Dept. of Food Technology \& Nutrition Science, Faculty of Science, Noakhali Science \& Technology University, Noakhali, Bangladesh. \\ ${ }^{1,2}$ School of Communication, Hong Kong Baptist University, Hong Kong. \\ DOI: https://doi.org/10.24321/0019.5138.202041
}

$\begin{array}{llll}\text { I } & \mathbf{N} & \mathbf{F} & \mathbf{O}\end{array}$

Corresponding Author:

Nahian Rahman, Dept. of Food Technology \& Nutrition Science, Faculty of Science, Noakhali Science \& Technology University, Noakhali, Bangladesh.

E-mail Id:

nahian.ftns@gmail.com

Orcid Id:

https://orcid.org/0000-0002-2899-7266

How to cite this article:

Kabir Md. R, Rahman N, lqbal A, Azad F, Tithi $\mathrm{SH}$, Uddin $\mathrm{MH}$ et al. Socio-demographic, Environmental and Life Style Factors on the Dengue Epidemic in Noakhali District, Bangladesh: Evidence from Recent Outbreak. J Commun Dis 2020; 52(4): 57-65.

Date of Submission: 2020-05-16

Date of Acceptance: 2020-09-16
$\begin{array}{llllllll}\mathbf{A} & \mathbf{B} & \mathbf{S} & \mathbf{T} & \mathbf{R} & \mathbf{A} & \mathbf{C} & \mathbf{T}\end{array}$

Background: Dengue, a mosquito-borne disease predominantly found in tropical and subtropical countries like Bangladesh. This study attempted to look at the influence of various socio-demographic, environmental, and lifestyle factors on the recent dengue outbreak in Noakhali district, Bangladesh.

Methods: The study adopted a mixed-method analysis of information collected from hospital records of dengue patients, and a telephone survey of the same patients to collect background information, their length of stay in the hospital, types of symptoms they had \& medicines they took, etc. Descriptive statistics, chi-square test, and logistic regression analysis were used for analysis.

Result: More than $80 \%$ of the patients were male, aged $<30$ years and resided in urban and semi-urban areas; $>60 \%$ of the patients got bitten by dengue vector at working place or while traveling, $>50 \%$ of the patients reported that they did not have proper sewage and garbage management at place. Patients living in urban areas were more likely to get infected with dengue than in other areas. Older patients ( $\geq 30$ years) were more likely to stay longer duration in hospital than younger ones. Moreover, men had higher chances of getting bitten at working place than women and children who were mostly bitten at household and surrounding environment $[\mathrm{OR}=14.7 ; \mathrm{P}=0.01]$.

Conclusion: Environmental, lifestyle, and socio-demographic factors had effects on dengue patients and their sufferings at the hospital. A safe working environment, proper sewage, and garbage management system, and organized urban development plan can help to reduce larvae development sites to a great extent.

Keywords: Dengue, Dengue Epidemic, Environmental \& Lifestyle factors, Noakhali District 


\section{Introduction}

Dengue fever, a mosquito-borne tropical disease caused by the dengue virus is a well-known phenomenon in recent era due to its severity across societies. In tropical and subtropical areas it is mainly occurred, especially Africa, Latin America, South East Asia and Oceania. ${ }^{1}$ Being considered a global health problem, every year it occurs in the world in the rainy season mainly when the environment is conducive for dengue breeding. ${ }^{2}$ Aedes type of mosquito transmits the dengue fever that was proved in 1906 and it was the second viral disease after yellow fever that was discovered in $1907 .{ }^{3}$ Aedes aegypti and A. albopictus are the two main vectors that are responsible for dengue fever ${ }^{4}$; however, four distinct serotypes of closely related vectors (DEN-1, DEN2, DEN-3, and DEN-4) are available which causes dengue hemorrhagic fever. ${ }^{5}$ Aedes aegypti is an urban vector, it is found mostly in urban area \& A. albopictus is found in rural and semi urban and forested area. ${ }^{6}$ Dengue virus is a type of RNA virus. Dengue fever has become a most horrible and emerging disease in South East Asian countries recently. Uncontrolled urbanization, lack of proper water and container management system are highly responsible for dengue virus development along with other factors. ${ }^{7}$

As dengue is mosquito-borne, its transmission pattern is strongly influenced by climate. Mostly occurs in cities, dengue virus is rapidly spreading largely due to urbanization, climate change and increased human movements found out by one study. However, dengue cases are not always distributed evenly throughout cities, where climate can be assumed to be homogenous. This suggests that other factors which are heterogeneously distributed in cities could play a role in dengue transmission, such as socioeconomic status and environmental factors. ${ }^{8}$ Various studies revealed that dengue has positive association with poor socio-economic status, low income, poor education, lack of concern and knowledge about dengue, unemployment status, household crowding, poor housing which includes inadequate sewage and garbage disposal, type of housing etc. ${ }^{9,10}$ But there are some studies which contradicts these finding stressed in one systematic review and these difference could be due to heterogeneity in measurements of socioeconomic indicators. ${ }^{11}$

However when it occurs, early treatment is important for reducing morbidity and mortality. ${ }^{12}$ Every year about 500,000 people get infected by dengue hemorrhagic fever and about 12,000 people die each year. ${ }^{13}$ Another report of WHO, estimated that 50-100 million people infected annually and 30 fold developed in last 50 years and among them about 20,000 deaths occur annually by dengue infection. ${ }^{14}$ Over 3.9 billion people from 128 countries live under the threat of dengue and 390 million infections occur every year, with 96 million people experiencing clinical manifestations of dengue. ${ }^{15}$ Plastic containers, tires, refrigerator trays, vehicle parts, discarded construction materials were significant predictors of dengue vector development. ${ }^{16}$

Bangladesh, a developing country with continuous economic development accompanied by rapid urbanization have experienced serious consequences of dengue fever in the last couple of years. According to a report of Directorate General of Health Services of Ministry of Health \& Family Welfare, Dhaka, Bangladesh, 16,223 people were infected with dengue in July, 2019 and 9,006 more till 6th August, 2019 and 18 of them died. ${ }^{17}$ Being an one of the populous countries in the world there are various changes happening; climate change one of the issues with unusual and heavy rainfall during summer and the unusual rise of temperature has positive relation with the dengue transmission and increased dengue risk. ${ }^{18}$

One study conducted by Mutsuddy $\mathrm{P}$ et al. in Bangladesh revealed that most of the dengue cases occurred during monsoon season (May-August) and post monsoon season (September-December); interestingly the study concludes that in the year 2015-17 the dengue cases were reported to be more than seven times higher in pre-monsoon season than the previous 14 years which sums up the danger season as pre to post monsoon for dengue risks in Bangladesh. They also claimed that climate changes, such as average rainfall, humidity, and temperature, after 2014, and rapid unplanned urbanization were the strong predictors which has led to increase in dengue cases. ${ }^{19}$ Various environmental, climatic and household factors aggravates dengue epidemics ${ }^{20}$; Containers, plastic bottles, cans and present of organic matters has positive association of dengue fever occurrences. ${ }^{21}$ Another study also concludes that environmental, social, economic and biological factors have positive association with dengue diseases. ${ }^{22}$ Climate, especially, temperature increases the mosquito bite, development rates and control the reproductive capacity of the virus within the mosquito 21 and it also affects human behavior and life style which also accelerate the dengue transmission dynamics in favor of cases development. ${ }^{23}$

Long time hospital stay has possibility to increasing dengue mortality and morbidity rate, dengue management system and inadequate public health infrastructure has positive association of dengue rate increasing. ${ }^{24}$ Various chemical, biological controlling method, and spraying have shown better result for preventing dengue larva development and decreasing breeding capacity of dengue; environmental control method also destroy the dengue growth media. ${ }^{25}$ However, it requires more in-depth analysis from different area specific and context specific observation and this study attempts to answer effects of all these factors by studying dengue patients who got admitted in Noakhali district, Bangladesh. 


\section{Survey Design \& Methodology}

The study adopted a mixed method analysis of information collected from hospital records of dengue patients who were reported as dengue patients by Noakhali General Hospital and telephone survey of the same patients to collect socio-demographic, environmental and various lifestyle data. The study considered all the 73 patients records that were available at hospital archives; however only 52 of the patients found available for telephone survey who enthusiastically participated in this study. The patients who were admitted to Noakhali General Hospitals were considered as patients and included in the study; however, patients who admitted to different private/public hospitals were not considered and hence not included in this study. The study material was a standard questionnaire and analysis of hospital records of patients. It included questions on general information of respondent's patients such as age, sex, hospital admission and release date, education, occupation, religion. It also included physical condition of patients, clinical conditions, comorbidities related conditions, environmental conditions, personal and living conditions. The survey had been carried out between January-March 2020. Telephone surveys were conducted in the day time from 10 a.m. to 5 p.m. on working days and from 10 a.m. to 12 p.m. on Friday, as working men and women are likely to be at home at this time. Data was analyzed using SPSS version 23, MS Excel after editing, coding and recoding. Descriptive statistics along with chissquare test and bivariate logistic regression were among the important analysis that have been performed; $P$-value $<0.1$ were considered as statistically significance with $90 \% \mathrm{Cl}$.

\section{Variables Measurement}

Categorization of some of the important variables were as follows: age of the patients $(<18,>18-29)$, area of residence (urban, semi-urban and rural), occupation (student/children, professional, labor/farmer, and housewife). In the bivariate logistic regression the categorization follows: where did you get bitten (home/surrounding environment vs. working place/travelling), how long you were admitted to hospitals ( $<7$ days vs. more than 7 days), how long you've waited to visit hospital (within 2 days vs. more than 2 days), did you know sign and symptoms of dengue (yes vs. no).

\section{Result}

\section{Socio-demographic Characteristics of the Study Patients}

Table 1, represents information about basic sociodemographic characteristics of the study patients. There were 45 male and 07 female patient. Most of the patients were Muslim and most of the patients were in moderate income group 36 (69.2\%) and rest of the patients can be considered as poor. From the frequency table of occupation, we came to know that most of the participant were employee or doing business. Only $14.3 \%$ of the patients were aged more than 30 years and only $28.8 \%$ of them had higher education and most of them were in normal physical state.

Table I.Basic socio-demographic characteristics

\begin{tabular}{|c|c|c|c|c|c|c|c|}
\hline Variables & \multicolumn{4}{|c|}{$n=52$} & \multirow{2}{*}{$\frac{\text { Variables }}{\text { Religion of the patient }}$} & \multicolumn{2}{|c|}{$n=52$} \\
\hline Sex of the patients & \multicolumn{2}{|c|}{$\mathbf{n}$} & \multicolumn{2}{|c|}{$\%$} & & $\mathbf{n}$ & $\%$ \\
\hline Male & \multicolumn{2}{|c|}{45} & \multicolumn{2}{|c|}{86.5} & Muslim & 49 & 94.2 \\
\hline Female & \multicolumn{2}{|c|}{7} & \multicolumn{2}{|c|}{13.5} & Hindu & 3 & 5.8 \\
\hline Patient age & \multicolumn{2}{|c|}{ Male } & \multicolumn{2}{|c|}{ Female } & Occupation of the patients & & \\
\hline$<18$ years & 15 & 3 & 33.3 & 42.9 & Student/ Children & 16 & 30.8 \\
\hline $18-29$ years & 24 & 3 & 53.3 & 42.9 & Professional (Employee/ Business) & 21 & 40.8 \\
\hline \multirow[t]{2}{*}{$\geq 30$ years } & 6 & 1 & 13.3 & 14.3 & Labor/farmer & 12 & 23.1 \\
\hline & & & & & Housewife & 3 & 5.8 \\
\hline \multicolumn{8}{|c|}{ Education status of the patients } \\
\hline Illiterate & \multicolumn{2}{|c|}{6} & \multicolumn{2}{|c|}{11.5} & Physical condition of the patients & & \\
\hline Primary & \multicolumn{2}{|c|}{13} & \multicolumn{2}{|c|}{25.0} & Normal & 44 & 84.6 \\
\hline Secondary & \multicolumn{2}{|c|}{18} & \multicolumn{2}{|c|}{34.6} & Overweight & 4 & 7.7 \\
\hline Higher Secondary & \multicolumn{2}{|c|}{15} & \multicolumn{2}{|c|}{28.8} & Underweight & 4 & 7.7 \\
\hline \multicolumn{8}{|c|}{ Monthly income the of the family } \\
\hline$<10000$ & 16 & 30.8 & & & & & \\
\hline$\geq 10000$ & 36 & 69.2 & & & & & \\
\hline
\end{tabular}




\section{Environmental \& Living Conditions of the Study Population}

Table 2, describes various environmental and living conditions of the study population. Around half of the patients were living in urban areas $(48.1 \%)$ and more than $55 \%$ of the patients did not have any sewage and garbage management system at place where they got bitten by mosquitos. Moreover, $61.5 \%$ of the patients reported that there were ponds, canals or rivers around the place where the incident happened. More than $44 \%$ of the patients bitten at their working place, $25 \%$ of them from their surrounding environment and the rest were got bitten while travelling or while staying at home.

\section{Clinical and Hospital-based Information}

Table 3, describes information about the clinical and hospital related information. The figure says around $42 \%$ of patients did not know about the sign and symptoms of the dengue and only 55.8\% used mosquito nets/coil/aerosol in living place. Hospital admission record says most of the patients got admission in hospital within 2-3 days after they have experienced symptoms. $51.9 \%$ of the patients stayed $4-7$ days in hospital and all of them had experienced fever and the next symptoms they had was headache; more than $70 \%$ of the patients were relied on traditional hospital medicine.

Figure 1, depicts hospital admission duration of patients in

Table 2.Environmental \& living conditions of the study population

\begin{tabular}{|c|c|c|c|c|c|}
\hline Study variables & \multicolumn{2}{|c|}{$\mathrm{n}=52$} & Study variables & \multicolumn{2}{|c|}{$n=52$} \\
\hline Location of the residence & $\mathbf{n}$ & $\%$ & \multicolumn{3}{|c|}{ Are there any bushes around? } \\
\hline Urban & 25 & 48.1 & Yes & 7 & 13.5 \\
\hline Suburb & 18 & 34.6 & No & 45 & 86.5 \\
\hline Rural & 9 & 17.3 & & & \\
\hline \multicolumn{3}{|c|}{ Sewage and garbage management system bitten place } & \multicolumn{3}{|c|}{ Is there have any ponds, River, Canal beside the area? } \\
\hline Yes & 23 & 44.2 & Yes & 32 & 61.5 \\
\hline No & 29 & 55.8 & No & 20 & 38.5 \\
\hline \multicolumn{3}{|c|}{ Is there any construction site around? } & \multicolumn{3}{|c|}{ Where did patient get bitten } \\
\hline Yes & 24 & 46.2 & Working place & 23 & 44.2 \\
\hline \multirow[t]{3}{*}{ No } & 28 & 53.8 & While Travelling & 10 & 19.2 \\
\hline & & & At home & 6 & 11.5 \\
\hline & & & Surrounding Environment & 13 & 25.0 \\
\hline
\end{tabular}

Table 3.Clinical and hospital related information

\begin{tabular}{|c|c|c|c|c|c|}
\hline \multirow{2}{*}{$\begin{array}{c}\text { Study variables } \\
\text { Knowing the sign and symptoms of dengue }\end{array}$} & \multicolumn{2}{|c|}{$\mathrm{n}=52$} & \multirow{2}{*}{$\begin{array}{c}\text { Study variables } \\
\text { Symptoms of the patient }\end{array}$} & \multicolumn{2}{|c|}{$n=52$} \\
\hline & $\mathbf{n}$ & $\%$ & & $\mathbf{n}$ & $\%$ \\
\hline Yes & 30 & 57.7 & Fever & 52 & 100.0 \\
\hline No & 22 & 42.3 & Severe headache & 34 & 65.4 \\
\hline \multicolumn{3}{|c|}{ Using of mosquito net/ coil/ aerosol in living place } & Muscle and joint pains & 18 & 34.6 \\
\hline Yes & 23 & 44.2 & Rash & 8 & 15.4 \\
\hline No & 29 & 55.8 & Abdominal pain & 7 & 13.5 \\
\hline \multicolumn{3}{|c|}{ How long patient waited to visit hospital } & Vomiting/ Nausea & 23 & 44.2 \\
\hline Within $1-2$ days & 22 & 42.3 & \multicolumn{3}{|c|}{ Type of medicine taken during dengue disease } \\
\hline Within 2-3 days & 23 & 44.2 & Traditional Medicine & 38 & 73.1 \\
\hline After 5 or more days & 7 & 13.5 & Home remedies & 14 & 26.9 \\
\hline \multicolumn{6}{|l|}{ How long patient were admitted in hospital } \\
\hline 3 or less days in hospital & 14 & 26.9 & & & \\
\hline 4-7 days in hospital & 27 & 51.9 & & & \\
\hline More than a week in hospital & 11 & 21.2 & & & \\
\hline
\end{tabular}


relation with their ages and the result reveals that patients who aged more than 30 years had to stay longer ( $6.57 \pm 1.9$ days) than their younger counterparts ( $4.89 \pm 3.57$ days).

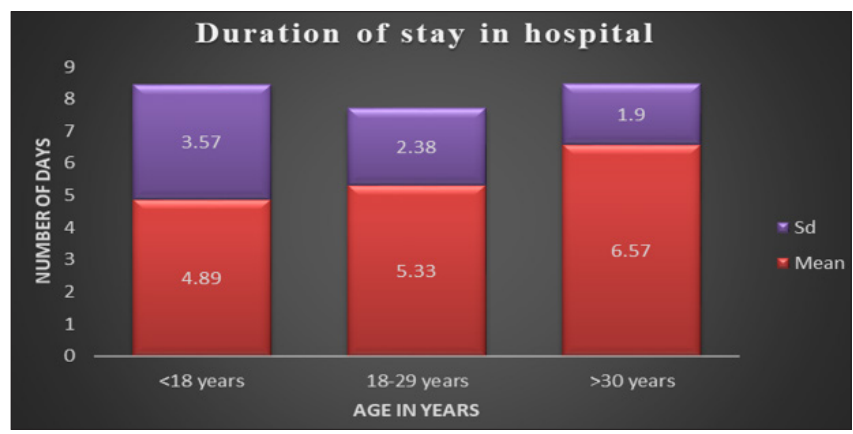

(Result derived from ANOVA test; Levene's statistic: 2.6; p-value: 0.079)

Figure I.Admission duration in hospital in relation with age

\section{Description of Prevalence of Socio-demographic, Environmental and Life Style Factors}

From the Table 4, it can be said that there is significant relationship between educational level and the knowledge about sign and symptoms of dengue. It shows that higher educated patients had more knowledge about sign and symptoms of dengue than lower educated. 93.3\% of the $\mathrm{HSC} /$ higher educated patients had knowledge about dengue sign and symptoms whereas the figure was mere $16.7 \%$ for patients who didn't have traditional education. Moreover, aged patients stayed long period of time in the hospital than the young patients. $42.9 \%$ of the patients above 30 years had stayed more than 7 days in hospital compared to $22.2 \%$ of patients of less than 18 years who stayed more than 7 days in the hospital.

From this study it was observed that there was corelationship between location of the residence and community hygiene maintenance. $72.0 \%$ of urban patient did not maintain community hygiene; the figures were much lower for the suburb and rural patients. This study found no significant relationship between sex of the patient and duration of stay in the hospital. There is no significant relationship between knowledge of the sign and symptoms of dengue and longevity of waiting to hospital visit. There was significant relationship between sex of the patient and the visibility of the symptoms of dengue. More number of women had experienced muscle and joint pains, rash than males and almost half of the patients had skin problems as comorbidities, 11 patients had respiratory problems and only few of them had other non-communicable diseases.

Table 4.Prevalence of socio-demographic, environmental and life-style factors

\begin{tabular}{|c|c|c|c|c|c|c|c|c|c|}
\hline \multicolumn{10}{|l|}{ Variables } \\
\hline \multirow{2}{*}{$\begin{array}{c}\text { Education } \\
\text { of the } \\
\text { patient }\end{array}$} & \multicolumn{3}{|c|}{$\begin{array}{l}\text { Knowledge about the sign and } \\
\text { symptoms of dengue }\end{array}$} & \multirow[t]{2}{*}{ P-value } & \multirow[t]{2}{*}{$\begin{array}{l}\text { Education of } \\
\text { the patient }\end{array}$} & \multicolumn{3}{|c|}{$\begin{array}{l}\text { Do you use mosquito net } \\
\text { in day time }\end{array}$} & \multirow[t]{2}{*}{ P-value } \\
\hline & Know & \multicolumn{2}{|c|}{ Don't know } & & & \multicolumn{2}{|c|}{ Yes } & No & \\
\hline $\begin{array}{l}\text { Illiterate/ } \\
\text { Children }\end{array}$ & 1 (16.7) & \multicolumn{2}{|c|}{$5(83.3)$} & \multirow{3}{*}{0.00} & $\begin{array}{l}\text { Illiterate/ } \\
\text { Children }\end{array}$ & \multicolumn{2}{|c|}{$3(23.1)$} & 10 (76.9) & \\
\hline Primary & $3(23.1)$ & \multicolumn{2}{|c|}{10 (76.9) } & & Primary & \multicolumn{2}{|c|}{$0(0.0)$} & $6(100)$ & 0.023 \\
\hline Secondary & $12(66.7)$ & \multicolumn{2}{|c|}{$6(33.3)$} & & Secondary & \multicolumn{2}{|c|}{$0(0.0)$} & $18(100)$ & \\
\hline $\begin{array}{l}\text { HSC/ Higher } \\
\text { Education }\end{array}$ & $14(93.3)$ & \multicolumn{2}{|c|}{$1(6.7)$} & 0.00 & $\begin{array}{l}\text { HSC/ Higher } \\
\text { Education }\end{array}$ & \multicolumn{2}{|c|}{$0(0.0)$} & $15(100)$ & 0.023 \\
\hline $\begin{array}{l}\text { Age of the } \\
\text { patient }\end{array}$ & \multicolumn{3}{|c|}{$\begin{array}{l}\text { How long you were admitted in } \\
\text { a hospital }\end{array}$} & & $\begin{array}{l}\text { Location of } \\
\text { the residence }\end{array}$ & \multicolumn{3}{|c|}{$\begin{array}{l}\text { Is community hygiene is } \\
\text { maintained? }\end{array}$} & \\
\hline & $\leq 3$ days & 4-7 days & $>7$ days & \multirow{4}{*}{0.088} & & & & No & \multirow{4}{*}{0.066} \\
\hline$<18$ years & $8(44.4)$ & $6(33.3)$ & $4(22.2)$ & & Urban & & 8.0) & $18(72.0)$ & \\
\hline $18-29$ years & $6(22.2)$ & $17(63.0)$ & $4(14.8)$ & & Suburb & 10 & $5.5)$ & $8(45.5)$ & \\
\hline$\geq 30$ years & $0(0.0)$ & $4(57.1)$ & 3 (42.9) & & Rural & & 6.6) & $3(33.4)$ & \\
\hline \multirow[t]{2}{*}{$\begin{array}{l}\text { Sex of the } \\
\text { patient }\end{array}$} & \multicolumn{3}{|c|}{$\begin{array}{l}\text { How long you were admitted in } \\
\text { a hospital }\end{array}$} & & $\begin{array}{l}\text { Knowledge } \\
\text { on sign and } \\
\text { symptoms of }\end{array}$ & \multicolumn{3}{|c|}{$\begin{array}{l}\text { How long you waited to } \\
\text { visit hospital }\end{array}$} & \\
\hline & $\leq 3$ days & 4-7 days & $>7$ days & 0.585 & & $\begin{array}{l}1-2 \\
\text { days }\end{array}$ & $\begin{array}{l}2-3 \\
\text { days }\end{array}$ & $\geq 5$ days & 0.225 \\
\hline
\end{tabular}




\begin{tabular}{|c|c|c|c|c|c|c|c|c|c|}
\hline Male & $11(24.4)$ & $24(53.3)$ & $10(22.2)$ & & Know & $\begin{array}{c}13 \\
(43.3)\end{array}$ & $\begin{array}{c}15 \\
(50)\end{array}$ & $2(6.7)$ & \\
\hline Female & $3(42.9)$ & $3(42.9)$ & $1(14.3)$ & & Don't know & $\begin{array}{c}9 \\
(40.9)\end{array}$ & $\begin{array}{c}8 \\
(36.4)\end{array}$ & $5(22.7)$ & \\
\hline $\begin{array}{c}\text { Sex of the } \\
\text { patient }\end{array}$ & Symptoms of dengue \\
\hline & Fever & Severe Headache & $\begin{array}{c}\text { Muscle and } \\
\text { Joint pains }\end{array}$ & Rash & $\begin{array}{c}\text { Abdominal } \\
\text { Pain }\end{array}$ & $\begin{array}{c}\text { Vomiting } \\
\text { /Nausea }\end{array}$ & \\
\hline Male & $45(100)$ & $29(64.4)$ & $14(31.1)$ & $6(13.3)$ & $6(13.3)$ & $19(42.2)$ & 0.000 \\
\hline Female & $7(100)$ & $5(71.4)$ & $4(57.1)$ & $2(28.6)$ & $1(14.3)$ & $4(57.1)$ & \\
\hline $\begin{array}{c}\text { Co } \\
\text { morbidities } \\
\text { response }\end{array}$ & $\begin{array}{c}\text { Ischemic } \\
\text { heart } \\
\text { disease }\end{array}$ & Obesity & Hematocrit & $\begin{array}{c}\text { Respiratory } \\
\text { problems }\end{array}$ & Diabetes & $\begin{array}{c}\text { Infection } \\
\text { (skin } \\
\text { allergy) }\end{array}$ & $\begin{array}{c}\text { Chronic } \\
\text { bronchial } \\
\text { asthma }\end{array}$ \\
\hline $\begin{array}{c}\text { Yes } \\
4\end{array}$ & 2 & 1 & 11 & 2 & 20 & 1 \\
\hline Percentage & $9.8 \%$ & $4.9 \%$ & $2.4 \%$ & $26.8 \%$ & $4.9 \%$ & $48.8 \%$ & $2.4 \%$ \\
\hline
\end{tabular}

(P-value derived from chi-square test; $p<0.1$ considered as statistical significant).

\section{Factors Associated with the Dengue Epidemic}

Table 5, describes the effect of different factors on different outcomes of dengue epidemic. According to the bivariate analysis, the female patients had 14.7 times higher risk of getting bitten by mosquito at home and surrounding environment than male who were working or on travel. Moreover, female patients waited more days to visit hospitals than their male counterparts and were two times less likely to know the sign and symptoms of dengue compared to male patients.

The study also showed that employees/business man are 0.104 times less likely to get bitten compared to students who stays at home and surrounding environment that means they got bitten in working place or travelling most often; students/children group also showed less knowledgeable than other groups since most of them were under aged children.

Table 5.Factors associated with different outcomes related to dengue disease

\begin{tabular}{|c|c|c|c|c|}
\hline Variables & $\begin{array}{l}\text { Where did you get bitten } \\
\text { (home/environment vs. } \\
\text { working place/travelling) }\end{array}$ & $\begin{array}{l}\text { How long you were } \\
\text { admitted } \\
\text { (<7 days vs. more } \\
\text { than } 7 \text { days ) }\end{array}$ & $\begin{array}{l}\text { How long you waited } \\
\text { to visit hospital } \\
\text { (within } 2 \text { days vs. } \\
\text { more than } 2 \text { days) }\end{array}$ & $\begin{array}{l}\text { Know sign and } \\
\text { symptoms of } \\
\text { dengue } \\
\text { (yes vs. no) }\end{array}$ \\
\hline & OR & OR & OR & OR \\
\hline \multicolumn{5}{|l|}{ Sex of the patient } \\
\hline Male & 1 & 1 & 1 & 1 \\
\hline Female & $14.7^{*}$ & .886 & 5.25 & 2.0 \\
\hline \multicolumn{5}{|c|}{ Occupation of the patient } \\
\hline Student/ Children & 1 & 1 & 1 & 1 \\
\hline Employee/ Business & $0.104^{*}$ & 1.5 & 1.03 & 2.0 \\
\hline Labor/ farmer & 0.000 & 2.14 & 1.08 & 1.57 \\
\hline Housewife & 0.667 & 0.000 & 1.55 & 4.40 \\
\hline \multicolumn{5}{|l|}{ Age of the patient } \\
\hline$<18$ year & 1 & 1 & 1 & 1 \\
\hline 18-29 year & 0.350 & 0.910 & 0.926 & $0.318^{*}$ \\
\hline$\geq 30$ year & 0.750 & 3.46 & 0.477 & 0.255 \\
\hline
\end{tabular}




\begin{tabular}{|c|c|c|c|c|}
\hline \multicolumn{5}{|l|}{ Education of the patient } \\
\hline Illiterate/ Children & 1 & 1 & 1 & 1 \\
\hline Primary & 0.222 & 0.889 & 1.12 & .667 \\
\hline Secondary & $0.100 *$ & 0.769 & 0.786 & $0.10 *$ \\
\hline HSC/ Higher education & 0.571 & 1.0 & 0.333 & $0.014^{*}$ \\
\hline \multicolumn{5}{|c|}{ Location of the residence } \\
\hline Urban & 1 & 1 & 1 & 1 \\
\hline Suburb & 2.53 & $3.16^{*}$ & 0.450 & 2.05 \\
\hline Rural & $3.95 *$ & 0.396 & 1.12 & $9.0^{*}$ \\
\hline
\end{tabular}

${ }^{*} p$-value at <0.1 level (results derived from bivariate logistic regression); OR: Odds Ratio.

Patient whose age is $18-29$ years were 0.350 times less likely to get bitten by mosquito at home and surrounding environment. Mainly they are bitten in outside of home such as working place, travelling etc. Higher educated persons are mostly get bitten outside of home and also knew about sign and symptoms of dengue compared to other groups. Moreover, rural patients had more chances to get bitten at home and surrounding environment than urban patients who mostly got bitten at working place or while travelling. Housewives were likely to wait more days to visit hospitals than other groups though the result is insignificant across all groups. And rural patients had 9.0 times less chance to know about the sign and symptoms than the urban patients.

\section{Discussion}

This particular study attempted to find the influence of socio-demographic, environmental and life style factors on the dengue epidemic in Noakhali district, Bangladesh and as far as socio-demographic and environmental factors concern, most of the patients were from urban and semiurban setting and their level of knowledge about sign and symptoms for dengue disease varied due to education level where patients with higher education knew the sign and symptoms of dengue epidemics more than their less educated counterparts; similar result was found in some studies conducted in Azad Kashmir, ${ }^{26}$ Vietnam $^{27}$ and Western Jamaica. ${ }^{28}$ Moreover, many patient's income status corresponds to medium to poor status by their income level and this finding is consistent with one study conducted in New Caledonia in urban setting which concluded that poor socioeconomic status of the population had a very robust correlation with dengue incidence. The possible explanation the study provided was poor socio-economy and unemployment influences lifestyle behaviors which may increase the risk of mosquito contact. ${ }^{8}$

A research conducted in Pakistan 7 found that most of the patients affected with dengue had fever $97.5 \%$, pain $40 \%$, vomiting $50 \%$, skin rash $20 \%$ which has similarity with our study findings where all patients experienced fever, along with pain $34.6 \%$, and vomiting $44.2 \%$ and skin rash $8 \%$. On the other hand, weather condition e.g. rainfall and humidity provide a vital impact on dengue epidemics and one study that conducted in Dhaka city ${ }^{29}$ showed that dengue mosquito Aedes aegypti is highly grown in rainy season which has indirect similarity with our study because most of the patients reported that they were affected by dengue during rainy season (June to October). ${ }^{30}$

Many patients also reported that there were ponds, canals or rivers around where they got bitten and more than $55 \%$ patients said there were no sewage and garbage management system at place which shows a poor environmental condition around and the study findings also showed similarity with one study which concludes the effect of unhealthy enviromental condition, poor housing, increased human mibility, unplanned urbanizations on increased dengue vector transmission. ${ }^{16}$ Life style factors which include use of mosquito net, coil or aerosol in the day and night revealed that more than half of the respondents (55.8\%) did not use moquito net, coil, aerosol in their living place and one study conducted in Karnataka ${ }^{31}$ provide signifigant result about the correlation between using mosquito net, coil, aerosol with reducing dengue epidemics. Moreover, as Aedes aegypti is a day biting mosquito that means the mosquito is most active during daylight, for approximately two hours after sunrise and several hours before sunset, but in our study all of the respondents $(100 \%)$ including literate and illiterate people did not use mosquito net or other measures in day time. Results of this study also concludes that older patients ( $\geq 30$ years) stayed more in hospital than the young ones which increases the likelihood of having more complicated cases and risk of mortality. ${ }^{24}$ Furthermore, females expereinced joint pains, rashes more often than males which might be another area needs to study further. Morever, labor and farmers had more chance to get bitten than other profession group which again shows the effect of poor socioeconomy. ${ }^{8}$ One study in Brazil also indicated that for older patients the relative risk of dengue increases significantly as the level 
of socio-environmental deprivation increases. ${ }^{9}$ Hence, comparsion with the findings of related study confirms the assoication of different environmental, sociodemographic and lifestyle factors on the dengue outbreak that happened in Noakhli district, Banladesh which is a rapdily growing city in Chittagong Divison, Bangladesh.

\section{Limitation}

This was a telephonic survey, hence had various limitation regarding data accuracy and reliability. Some male and female patient afraid to give information to the unknown person. Our project was held on February but dengue outbreak was severed in July to September; because of time gap patient didn't remember correctly some of our study information. The study did not consider many other factors. Moreover, the hospital recording of patient's information weren't digitalized and some of the files were really torn and difficult to read or to draw information out.

\section{Conclusion}

Dengue fever is a dangerous and depilating disease and a serious public health concern in Bangladesh causing a mass hysteria, panic and disruption of lives in recent years. This study tried to find out whether the recent outbreak has any relation with the titled factors and the study did find some association with these important factors. These findings could be valuable which might help Bangladesh to take proper steps, intervention and aware the mass population.The biggest issue is that dengue fever is spreading fast all over the world but currently has no specific treatment or vaccine for it and a developing country like Bangladesh always struggles to keep up when the cases are rising. In recent years it has become one of the leading causes of hospitalization and death among children and vulnerable people and become a massive threat to health system to bear. Environmental cleaning, sanitation, maintaining cleanliness around living and working place, planned infrastructure development, proper garbage and disposal system, concern about dengue disease, using various preventive measures, improving socioeconomic status might provide strong positive benefits in terms of controlling dengue vector development, reducing dengue cases or to minimize sufferings if cases occurs.

\section{Acknowledgement}

The authors would like to acknowledge the support of Department of Food Technology \& Nutrition Science \& Research Cell, Noakhali Science \& Technology University (NSTU). The authors also would like to acknowledge the support of Research Cell, NSTU. The author also want to thank Noakhali General Hospital and the authority especially Residential Medical Officer (RMO) for their cordial support to conduct this study.

\section{Funding Declaration}

There is no funding to be disclosed.

\section{Competing Interests}

The authors declare that they have no competing interests.

\section{Ethical Approval}

This study was carried out by undertaking proper permission from ethical committee of NSTU and strictly maintained all the ethical guidelines. Approval for the study was also obtained from the Civil Surgeon Office Noakhali, Noakhali Sadar Upazila Health Complex, RMO and Superintendent of the hospital.

The study was conducted in accordance with the Helsinki Declaration where require; all the participants were well aware of the study pros and cons and upon their consent this observational study was conducted. All the study subjects participated enthusiastically and cooperated during the whole study.

\section{Conflict of Interest: None}

\section{References}

1. Yang T. Epidemiology and vector efficiency during a dengue fever outbreak in Cixi, Zhejiang Province, China. Journal of Vector Ecology 2009; 34(1): 148-154.

2. Rahman M. First outbreak of dengue hemorrhagic fever, Bangladesh. Emerging Infectious Diseases 2002; 8(7): 738.

3. Srinivas V, Srinivas VR. Dengue fever: A review article. Indian J Med Res 2011.

4. Nishiura H, Halstead SB. Natural history of dengue virus (denv)-1 and denv-4 infections: Reanalysis of classic studies. The Journal of Infectious Diseases 2007; 195(7): 1007-1013.

5. Gubler DJ, Clark GG. Dengue/dengue hemorrhagic fever: the emergence of a global health problem. Emerging Infectious Diseases 1995; 1(2): 55.

6. Van Benthem BHB. Spatial patterns of and risk factors for seropositivity for dengue infection. The American Journal of Tropical Medicine and Hygiene 2005; 72(2): 201-208.

7. Khan J. Epidemiological trends and risk factors associated with dengue disease in Pakistan (19802014): a systematic literature search and analysis. BMC Public Health 2018; 18(1): 745.

8. Zellweger RM. Socioeconomic and environmental determinants of dengue transmission in an urban setting: An ecological study in Nouméa, New Caledonia. PLoS Neglected Tropical Diseases 2017; 11(4): e0005471.

9. Costa JV, Donalisio MR, Silveira LVDA. Spatial distribution of dengue incidence and socio-environmental 
conditions in Campinas, São Paulo State, Brazil, 2007. Cadernos de saude Publica 2013; 29(8): 1522-1532.

10. Hagenlocher M. Assessing socioeconomic vulnerability to dengue fever in Cali, Colombia: statistical vs expertbased modeling. International Journal of Health Geographics 2013; 12(1): 36.

11. Mulligan K. Is dengue a disease of poverty? A systematic review. Pathog Glob Health 2015; 109 (1): 10-18.

12. Gupta V. Risk factors of dengue shock syndrome in children. Journal of Tropical Pediatrics 2011; 57(6): 451-456.

13. Ahmed S. Dengue fever outbreak: a clinical management experience. J Coll Physicians Surg Pak 2008; 18(1): 8-12.

14. Malavige GN. Dengue viral infections. Postgraduate Medical Journal 2004; 80(948): 588-601.

15. Bhatt $S$. The global distribution and burden of dengue. Nature 2013; 496(7446): 504-507.

16. Paul KK. Risk factors for the presence of dengue vector mosquitoes, and determinants of their prevalence and larval site selection in Dhaka, Bangladesh. PloS One 2018; 13(6).

17. Akram A. Alarming turn of dengue fever in Dhaka city in 2019. Bangladesh Journal of Infectious Diseases 2019; 6(1): 1-2

18. Banu S. Projecting the impact of climate change on dengue transmission in Dhaka, Bangladesh. Environment International 2014; 63: 137-142.

19. Mutsuddy P. Dengue situation in Bangladesh: An epidemiological shift in terms of morbidity and mortality. Canadian Journal of Infectious Diseases and Medical Microbiology 2019.

20. Jansen CC, Beebe NW. The dengue vector Aedes aegypti: what comes next. Microbes and Infection 2010; 12(4): 272-279.

21. Tun-Lin W, Burkot TR, Kay BH. Effects of temperature and larval diet on development rates and survival of the dengue vector Aedes aegypti in north Queensland, Australia. Medical and Veterinary Entomology 2000; 14(1): 31-7.

22. Dhar-Chowdhury P. Dengue seroprevalence, seroconversion and risk factors in Dhaka, Bangladesh. PLoS Neglected Tropical Diseases 2017; 11(3): e0005475.

23. Beebe NW. Australia's dengue risk driven by human adaptation to climate change. PLoS Neglected Tropical Diseases 2009; 3(5).

24. Pooransingh SS, Dialsingh I. Dengue deaths: associated factors and length of hospital stay. Advances in Preventive Medicine, 2016.

25. George L. Community-effectiveness of temephos for dengue vector control: a systematic literature review. PLoS Neglected Tropical Diseases 2015; 9(9).

26. Habib N, Aziz W, Ashaq A. Dengue fever: a statistical analysis regarding awareness about dengue among university students in Azad Kashmir. Journal of Healthcare Communications 2016; 2(1): 1.

27. Nguyen HV. Knowledge, attitude and practice about dengue fever among patients experiencing the 2017 outbreak in Vietnam. International Journal of Environmental Research and Public Health 2019; 16(6): 976.

28. Alobuia WM. Knowledge, attitude, and practices regarding vector-borne diseases in Western Jamaica. Annals of Global Health 2015; 81(5): 654-663.

29. Ahmed TU. Some socio-demographic factors related to dengue outbreak in Dhaka City, Bangladesh. Bangladesh J Zool 2007; 35: 213-222.

30. Chakravarti A, Kumaria R. Eco-epidemiological analysis of dengue infection during an outbreak of dengue fever, India. Virology Journal 2005; 2(1): 32.

31. Kamath R. Assessment of environmental factors associated with dengue transmission in Udupi Taluk, Karnataka. Journal of the Scientific Society 2013; 40(3): 159. 